Rees, R. J. W., Valentine, R. C. \& Wong, P. C. (1960). J. gen. Microbiol. 22, 443-457

\title{
Application of Quantitative Electron Microscopy to the Study of Mycobacterium lepraemurium and M. leprae
}

\author{
Bx R. J. W. REES, R. C. VALENTINE AND P. C. WONG* \\ The National Institute for Medical Research, Mill Hill, London, N.W. 7
}

SUMMARY: The standard methods for assessing viability of micro-organisms are not applicable to rat and human leprosy bacilli since neither organism can be grown in vitro. McFadzean \& Valentine $(1958,1959)$ suggested that the electron microscope might provide a quantitative guide to the viability of these organisms by allowing dead forms to be identified. This technique is further investigated and shown to be valid and reasonably accurate for Escherichia coli provided the organisms are not morphologically fixed by the killing agent. It is concluded that the method can assess death of leprosy bacilli in the host when this occurs either naturally or aided by bactericidal drugs, and also loss of viability on storage, but not sudden killing by more violent chemical or physical means. The method has been found useful for following the survival of Mycobacterium lepraemurium in tissue cultures. It is suggested that death in the host but not death occurring on storage can be measured by a simple classification of the bacilli seen with the light microscope after the conventional carbol fuchsin stain. It is indicated that many of the bacilli obtained from untreated human cases of leprosy are dead, while from rats the percentage which is degenerate is low. The significance of various features of the leprosy bacilli seen with the electron microscope is discussed. There is no evidence that the bacilli form spores or capsules.

Several studies of rat and human leprosy bacilli made with the electron microscope (Bishop, Suhrland \& Carpenter, 1948; Brieger \& Glauert, 1956a; Chapman, Hanks \& Wallace, 1959) have revealed in considerable detail the fine structure of the bacilli and the relation of the bacilli to the infected host cells; in those studies no attempt was made to correlate differences in the internal structure of the organisms with biological activity. McFadzean \& Valentine $(1958,1959)$ suggested that electron microscopy can provide a quantitative measure of the viability of leprosy bacilli under certain conditions. The standard methods for assessing viability cannot be applied to these organisms since neither the bacillus of human leprosy (Mycobacterium leprae) nor the closely related organism of rat leprosy (M. lepraemurium) has yet been grown in any culture media in vitro. Furthermore, no susceptible experimental animal is available for determining the viability of $M$. leprae and titrations of $M$. lepraemurium in rats or mice take several months. We report here further investigations of the value and significance of electron microscope observations for determining the viability of leprosy bacilli under different conditions in vitro and in vivo.

* Present address : Department of Pathology and Bacteriology, University of Hong Kong. 


\section{METHODS}

\section{Suspensions of leprosy bacilli}

Mycobacterium lepraemurium. The Douglas strain of Mycobacterium lepraemurium (Balfour-Jones, 1937) was used throughout. Subcutaneous or peritoneal leproma from infected rats (hooded strain) or liver from mice (albino $\mathbf{P}$ strain) infected intravenously with a partially-purified suspension of bacilli (Rees, $1957 a$ ) was minced with scissors and ground to a smooth suspension in a sterile mortar or tissue-grinder. The suspension was prepared in $1 \%(\mathrm{w} / \mathrm{v})$ albumin (bovine plasma fraction $\mathrm{V}$ ) in $0.85 \%(\mathrm{w} / \mathrm{v}) \mathrm{NaCl}$ solution (albumin saline). The crude suspension was centrifuged at $1500 \mathrm{rev} . / \mathrm{min}$. for $5 \mathrm{~min}$. to remove tissue fragments and clumps of bacilli. The supernatant fluid was removed, centrifuged at $5000 \mathrm{rev} . / \mathrm{min}$. for $5 \mathrm{~min}$. and the resulting supernatant fluid discarded. The sediment was resuspended in a volume of albumin saline to give not less than $10^{7}$ acid-fast bacilli $/ \mathrm{ml}$. and counted by the method described by Rees \& Wong (1958). In most of these suspensions the bacilli were well dispersed, predominantly as single organisms. Suspensions containing clumped bacilli were dispersed by exposure to ultrasonic vibration for 1530 sec. (Garbutt, Rees \& Barr, 1958), a procedure which did not damage the bacilli (Wong, 1957).

Mycobacterium leprae. Heavily infected biopsy material was obtained mainly from East and West Africa from patients with lepromatous leprosy who had received no known treatment. The material was dispatched by air, on ice, in specially constructed containers (Brown \& Rees, 1959) and was processed within $72 \mathrm{hr}$. of removal from the patient. The method for preparing a suspension of human leprosy bacilli was the same as that used for rat bacilli except for the addition of small amounts of silver-sand to assist homogenization. The suspensions of Mycobacterium leprae generally contained a higher proportion of tissue homogenate, particularly collagen, than the suspensions of $M$. lepraemurium and the bacilli were more clumped.

\section{Preparation of bacilli for electron microscopy}

The suspension of bacilli in albumin saline was fixed by adding formaldehyde to final concentration $2 \%(w / v)$. A drop was then placed on the electron microscope support, left for 2 min., and the support washed briefly by immersion in distilled water, blotted at the edge with filter paper and allowed to dry. Where the initial concentration of bacilli was not less than $10^{7} \mathrm{bacilli} / \mathrm{ml}$. this method gave an adequate and representative sample of bacilli well dispersed over the film. When it was necessary to use lower concentrations of bacilli, the suspension was centrifuged and resuspended in distilled water several times and a drop then dried directly on the support. The minimum count of bacilli/ $\mathrm{ml}$. required depends on the amount of tissue debris present in the sample, but our experience has been that concentrations of less than $10^{6} \mathrm{bacilli} / \mathrm{ml}$. seldom allowed enough bacilli to be sufficiently clearly seen for quantitative work. This is the chief limitation of the electron microscope technique; with the light 
microscope, where the bacilli can be selectively stained, far lower concentrations can be examined, even in the presence of much debris.

\section{Infectivity of Mycobacterium lepraemurium in mice}

Suspensions of bacilli were inoculated into mice in $0.1 \mathrm{ml}$. saline, intradermally, to form a bleb in the skin of the abdomen, by using a tuberculin-type syringe with a 1 in. needle (s.w.G. 26). The needle was introduced low down on the abdomen and pushed forward so that the bleb was produced just below the sternum, in the mid-line. Five or six mice (albino P strain) were used for each dose tested. The skin over the abdomen was inspected and palpated weekly for the presence of a leprosy nodule.

\section{Cultures of Escherichia coli}

Escherichia coli strain 88 used in this work was maintained on Hedley Wright broth agar slopes and freshly subcultured into similar liquid medium for each experiment. All colony counts were made by spreading samples of $0.003 \mathrm{ml}$. from a standard platinum wire loop, from successive $1 / 10$ dilutions, on well dried plates of broth agar. Three dilutions were spread on each plate, each dilution in triplicate.

\section{RESULTS}

Appearance of Mycobacterium lepraemurium recovered from the tissues of mice and rats

The bacilli of Mycobacterium lepraemurium obtained from homogenates of infected tissue from rats and mice presented a uniform appearance in the electron microscope. The bacilli had lengths narrowly scattered around a mean of $1.65 \mu$ and differed from other rod-shaped bacteria mainly in their unusually narrow width $(0 \cdot 3 \mu)$. Darker internal features were often seen even in unsectioned organisms; we frequently observed small spherical bodies of high electron-scattering power. These bodies evaporated readily in the electron beam and were almost certainly deposits of metaphosphates (volutin granules; Bradfield, 1956). Larger but less dense bodies, often filling the entire width of the bacilli, were frequently seen particularly in a polar position. Their nature is more controversial, but there is evidence that, in other mycobacteria, they occupy sites where oxidation-reduction reactions occur particularly vigorously (Mudd, Takeya \& Henderson, 1956). Such bodies may thus be functional equivalents of mitochondria of higher cells though they admittedly bear no structural resemblance to them.

The bacilli were surrounded by a cell wall about $150 \mathrm{~A}$ thick, but no layer of material that could be interpreted as capsule was seen. The typical electron microscope appearance described is illustrated by Pl. 1, fig. 1. Other less usual features seen under certain conditions are described subsequently. 


\section{Changes in the appearance and infectivity of Mycobacterium lepraemurium incubated in phosphate buffer}

Hanks (1952, 1954) showed that suspensions of Mycobacterium lepraemurium in phosphate buffer, left at $37^{\circ}$ for 28 days, lost almost all their initial viability but remained fully infectious at $4^{\circ}$. This provides a convenient method of obtaining comparable suspensions of $\boldsymbol{M}$. lepraemurium differing markedly in viability. McFadzean \& Valentine $(1958,1959)$ reported that the bacilli in the two kinds of suspension had very different appearances in the electron microscope; those incubated at $37^{\circ}$ showed clear signs of complete degeneration. They confirmed by inoculating rats that this $37^{\circ}$ suspension was non-infectious, implying a correlation between the electron microscope appearance and loss of viability.

The only quantitative method available for assessing the viability of Mycobacterium lepraemurium is to inject known numbers of bacilli (in serial dilutions) into the skin of mice. We attempted to correlate the quantitative measures of viability obtained in this way with the proportion of bacilli showing changes in morphology as seen in the electron microscope. A suspension containing c. $10^{10} \mathrm{bacilli} / \mathrm{ml}$. was prepared from a 6-months-old rat leproma. The suspension was centrifuged and the deposit washed and finally resuspended in $0.01 \mathrm{M}$ phosphate buffer ( $\mathrm{pH} 7$ ). Samples of the original suspension were kept at $4^{\circ}$ and $37^{\circ}$. Samples of bacilli were examined in the electron microscope at the start of the experiment, and 14 and 28 days later. After 28 days at $37^{\circ}$ most of the bacilli had the appearance shown in $\mathrm{Pl}$. 1, fig. 2. The cell wall was no longer uniformly filled, but contained dense aggregates of disorganized material and was otherwise empty. It is assumed, from the disorganized appearance of their protoplasm, that this form of organism was non-viable; bacilli showing these appearances will be termed 'degenerate'. Most of the bacilli kept at $4^{\circ}$, on the other hand, retained their normal appearance as shown in $\mathrm{Pl}$. 1, fig. 1. The percentage of the degenerate forms of the bacilli at the start, day 14 and day 28 are shown in Table 1 . Although $94 \%$ of the bacilli appeared degenerate in the electron microscope when incubated at $37^{\circ}$ for 28 days, they stained well with carbol fuchsin and were indistinguishable from the bacilli freshly isolated from the rat. Furthermore, even when incubation was continued for $\mathbf{2 0 3}$ days the bacilli still stained uniformly and showed no beading.

To test the viability of the bacilli, as judged by infectivity in animals, samples of the suspensions initially and after storage for 28 days at $4^{\circ}$ and $37^{\circ}$, respectively, were injected into mice. The number of bacilli (counted as acidfast bacilli) was determined for the three samples and then each adjusted to contain $3 \times 10^{7}$ bacilli $/ \mathrm{ml}$. Serial $1 / 10$ dilutions of each sample were made covering the range from $3 \times 10^{7}$ to 3 bacilli $/ \mathrm{ml}$. A sample of $0.1 \mathrm{ml}$. was injected intradermally into five or six mice from each dilution. The skin at the site of the injection was inspected and palpated for the presence of a leprosy nodule weekly for 53 weeks. The average time, in weeks, for the development of a nodule for each dose of bacilli is also given in Table 1. When the results for each dilution 


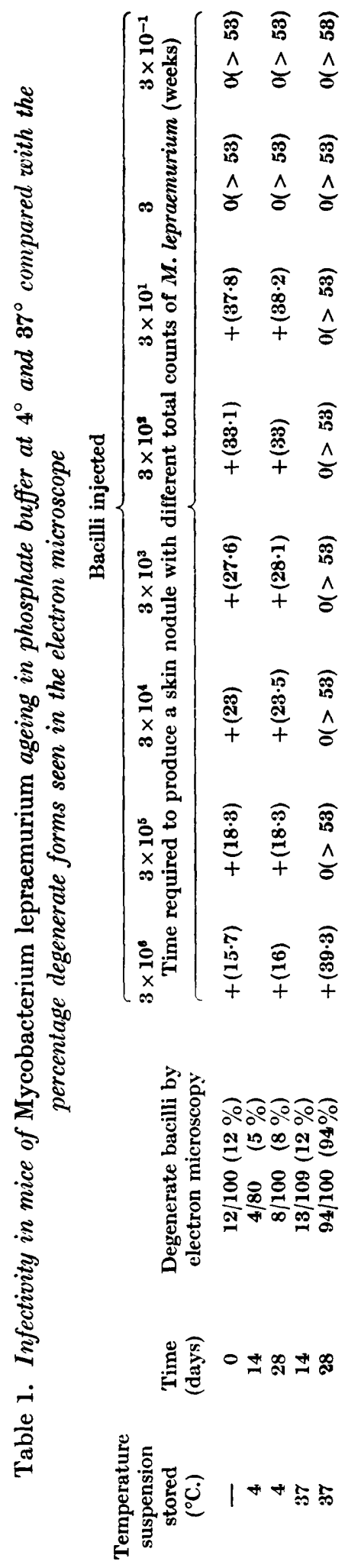

447 
of the fresh suspension are compared with those for the suspension stored for 28 days in phosphate buffer at $4^{\circ}$, an almost exact correspondence in the times taken for lesions to appear is evident. Thus very little loss of viability at this temperature can have occurred. The electron microscope showed that the proportion of degenerate forms had not increased. The infectivity of the suspension stored at $37^{\circ}$, on the other hand, had fallen by a factor of $10^{5}$. The electron microscope reflected this fall by showing $95 \%$ degenerate forms, indicating that the electron microscope count may underestimate viability by about $5 \%$.

Changes in the appearance and viability of Escherichia coli incubated in phosphate buffer

A correlation between loss of viability and the obviously degenerate appearance in the electron microscope could be followed more precisely by using an organism such as Escherichia coli which will rapidly multiply in a conventional medium. On incubating at $37^{\circ}$ in phosphate buffer these organisms showed a similar change from the initial homogeneous appearance (PI. 1, fig. 3) to the disorganized and degenerate appearance (Pl. 1, fig. 4) seen with

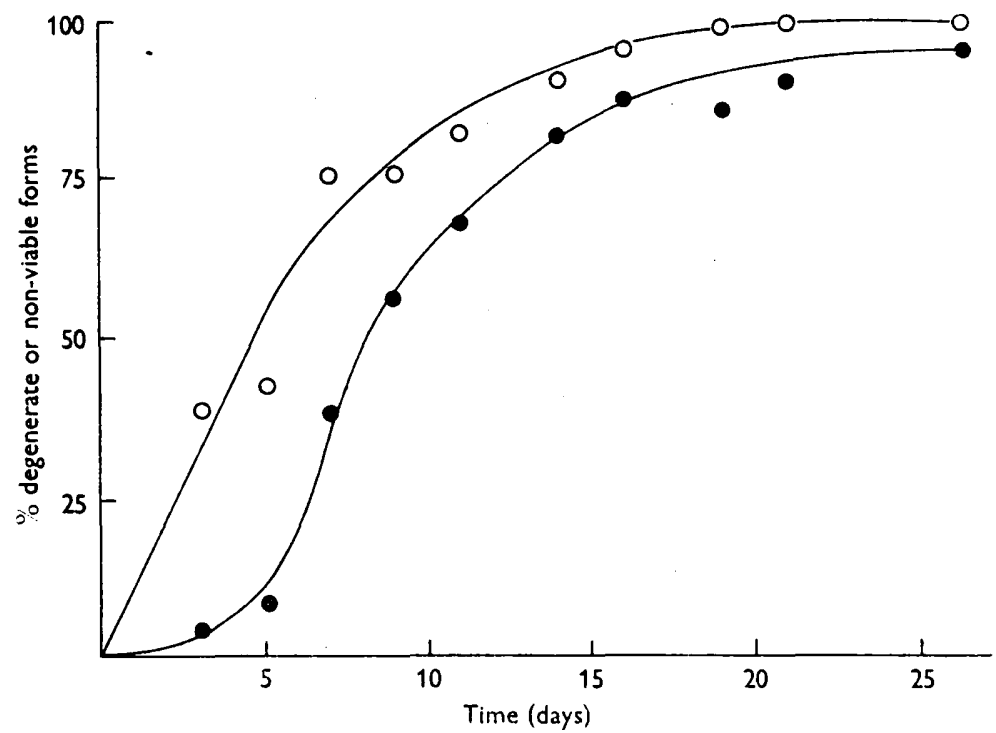

Fig. 1. Washed suspensions of Escherichia coli in $0.01 \mathrm{~m}-$ phosphate buffer (pH 7 ) sampled during incubation at $37^{\circ}$. $=\%$ degenerate forms of bacilli of not less than 100 organisms examined in the electron microscope; $0=\%$ non-viable bacilli determined from the decrease in colony count.

Mycobacterium lepraemurium. The percentage of degenerate forms seen in the electron microscope after different times of incubation together with the viable counts made on the same samples is shown in Fig. 1. The two curves are similar in shape but separated by a 2- to 3-day delay which is presumably the time required for a non-viable organism to acquire a morphologically degenerate appearance. Some $5 \%$ of the bacilli failed ever to assume this form. 
The experiment was repeated with suspensions initially rendered non-viable by one of the following treatments: $0.01 \mathrm{~N}$-hydrochloric acid; ultraviolet radiation $\left(c .10^{6} \mathrm{ergs} / \mathrm{cm}^{2}\right)$; rapid cooling to $4^{\circ}$ (Meynell, 1958). In none of these pretreatment suspensions had any degenerate forms appeared, even after subsequent incubation for 28 days at $37^{\circ}$ in phosphate buffer. All these treatments immediately destroyed viability but apparently 'fixed' the morphology of the bacillus in the normal form.

Biological significance of the segmented form of Mycobacterium lepraemurium

The electron microscope showed a third distinct form of Mycobacterium lepraemurium in which most or all of the organisms were divided into many clearly outlined and frequently dense bodies (Pl. 1, fig. 5). This appearance was often seen in suspensions of bacilli prepared from infected tissue cultures of monocytes or from bacilli incubated at $37^{\circ}$ for many weeks in medium containing high concentrations of citrate (Dr P. d'A. Hart; personal communication). The segmented form found in citrate medium usually changed to the degenerate form on continued incubation. Although in some of the tissue culture specimens up to $50 \%$ of the bacilli were of the segmented type, in citrate medium the percentage was lower, usually about $10 \%$. In order to determine the viability of this type of organism suspensions were injected into the skin of mice and observed for the development of leprosy nodules. For these tests the suspensions were obtained from bacilli which had been incubated at $37^{\circ}$ for 54 days in media containing citrate. Bacilli from three different media were centrifuged and concentrated by resuspending in a smaller volume of albumin saline. Samples of each were examined in the electron microscope for the proportion of segmented forms, and standard stained smears were prepared for counting the number of acid-fast bacilli. Six mice were inoculated intradermally with $0 \cdot 1 \mathrm{ml}$. of each suspension. The inocula contained $5 \times 10^{5}, 2 \times 10^{6}$ and $3 \times 10^{6}$ of segmented bacilli, representing 10,5 and $7 \%$, respectively, of the total acid-fast bacilli present; the remainder all appeared to be degenerate. The animals were observed for 10 months during which time none developed skin nodules. These segmented forms of $M$. lepraemurium were therefore not viable.

\section{Appearance of Mycobacterium lepraemurium recovered from heavily infected mice receiving isoniazid}

Electron microscope examination of many samples of bacilli recovered from untreated rats or mice experimentally infected with Mycobacterium lepraemurium always showed a high proportion of normal forms of bacilli, even when the infection had been established for a year. So far the transformation from normal to degenerate forms had only been observed in vitro either in suspension or in tissue culture. Therefore a group of mice with far advanced leprosy, infected intravenously 4 months previously, were treated with isoniazid $(0.02 \%, w / v$, in the diet) since this compound is known to have high chemotherapeutic activity against murine leprosy (Goulding, Robson \& Rees, 1953). 
A group of similar mice was left untreated. Suspensions of bacilli were prepared for examination in the electron microscope from liver and spleen of two or three mice killed before beginning treatment with isoniazid, 28 days later from the treated and untreated groups, and 69 and 273 days later from the treated group. Although all the untreated mice had died before day 69 with advanced and generalized leprosy none of those which received isoniazid had died. Furthermore, there was a very significant and rapid increase in the proportion of degenerate bacilli recovered from the tissues of treated mice (Table 2). Identical samples of bacilli prepared for electron microscopy from the treated and untreated group on day 28 were spread on slides and stained by the Ziehl-Neelsen method and examined in the light microscope. Except for a slight decrease in the intensity of staining with carbol fuchsin of the bacilli from the treated mice the two samples were indistinguishable (Pl. 2, figs. 8, 9). On the other hand, bacilli stained with carbol fuchsin from mice which had received isoniazid for 69 days or longer were definitely abnormal. The staining was generally less intense and irregular, giving the bacilli a beaded appearance.

Table 2. Percentages of degenerate Mycobacterium lepraemurium recovered from the tissues of untreated mice and mice receiving isoniazid (0.02\%) in diet

$\begin{array}{ccc}\begin{array}{c}\text { Period of } \\ \text { treatment } \\ \text { (days) }\end{array} & \begin{array}{c}\text { M. lepraemurium seen by electron } \\ \text { microscopy (\%) }\end{array} \\ & \begin{array}{c}\text { Isoniazid } \\ \text { treated mice }\end{array} & \begin{array}{c}\text { Untreated } \\ \text { mice }\end{array} \\ 28 & - & 9(9 / 100) \\ 69 & 93(56 / 77) & 13(15 / 115) \\ 273 & 95(195 / 206) & -*\end{array}$

* All untreated mice died with advanced leprosy before day 69.

Mycobacterium lepraemurium in tissue cultures

Because rat leprosy bacilli have not been cultivated in bacteriological type media two of us (R.J.W.R. and P.C.W.) attempted to grow the bacilli in tissue cultures. The general tissue culture methods and special technique used for following the number of Mycobacterium lepraemurium organisms in infected cultures of mouse monocytes and of spleen explants were described elsewhere (Rees \& Wong, 1958). With a slowly multiplying organism of this kind, which divides every 12-13 days in vivo (Rees, 1957 $b$ ), many weeks would be required to show a really significant increase in the number of $M$. lepraemurium organisms in tissue culture. On the other hand, since $M$. lepraemurium dies in 2-3 weeks when incubated in cell-free media, prolonged survival of bacilli in tissue-culture cells would, in itself, provide a valuable guide to the choice of suitable cultural conditions. Hitherto survival has been measured as continued infectivity of bacilli put back into a susceptible animal, requiring many weeks to determine. Electron microscopy was therefore used as an indirect but much 
more rapid method for following the survival of $M$. lepraemurium in tissue cultures (Rees, Valentine \& Wong, 1958). Each time a sample of bacilli was removed from the tissue cultures for counting, a sample was examined in the electron microscope to determine the proportion of degenerate forms. The results of some of these studies are shown in Table 3.

Table 3. Survival of Mycobacterium lepraemurium during incubation in a variety of media and in tissue cultures

\begin{tabular}{|c|c|c|c|c|c|c|c|c|}
\hline \multirow{3}{*}{$\begin{array}{c}\text { Medium } \\
\text { 0.01 } \text { m-phosphate } \\
\text { buffer (pH 7) }\end{array}$} & \multirow{3}{*}{ 'Tissue culture } & \multirow{3}{*}{$\begin{array}{c}\text { Condition of } \\
\text { tissue culture } \\
-\end{array}$} & \multicolumn{6}{|c|}{ Age of culture (days) } \\
\hline & & & \multicolumn{6}{|c|}{$\begin{array}{c}\text { Degenerate forms of } M \text {. lepraemurium } \\
\text { by electron microscopy }(\%)\end{array}$} \\
\hline & & & 6 & 13 & 97 & 99 & - & $\ldots$ \\
\hline $\mathbf{A}$ & - & - & 10 & $\mathbf{2 0}$ & 96 & 99 & - & - \\
\hline $\mathbf{A}$ & Mouse monocytes* & Healthy & $\mathbf{9}$ & - & 一 & 17 & - & $\mathbf{5 8} \dagger$ \\
\hline $\mathbf{A}$ & Mouse monocytes* & Degenerate & $\mathbf{9}$ & - & - & $\mathbf{5 3}$ & - & 98 \\
\hline $\mathbf{B}$ & - & - & 10 & 20 & 55 & 99 & - & - \\
\hline $\mathbf{B}$ & Mouse spleen explants $\ddagger$ & Healthy & 10 & - & 18 & - & 27 & - \\
\hline B+INH and SM & Mouse spleen explants* & Healthy & $\mathbf{9}$ & - & 57 & - & 81 & - \\
\hline \multicolumn{9}{|c|}{$A=$ medium 199 (Morgan, Morton \& Parker, 1950) + $2.5 \%$ mouse embryo extract (MEE); $0.5 \%$ bovin } \\
\hline
\end{tabular}

When suspensions of bacilli were incubated in the tissue culture media alone they degenerated as rapidly as in phosphate buffer. On the other hand, intracellular bacilli, within mouse monocyte or spleen cells, degenerated significantly less rapidly even when the host cells were incubated in the same tissue culture media. Little protection was afforded by degenerate host cells. Although the survival of bacilli within monocytes was prolonged, there was no evidence of the organisms dividing. The spleen cells provided greater protection against degeneration and within these cells limited multiplication was observed. Addition of high concentrations of two antileprosy drugs, isoniazid and streptomycin, to the infected spleen cultures not only inhibited multiplication of the bacilli but resulted in an increase in the proportion of degenerate bacilli.

\section{Appearance of Mycobacterium leprae recovered from human lepromatous nodules}

Twenty samples of suspensions of Mycobacterium leprae were examined in the electron microscope. The size and general appearance of the organisms were found to be indistinguishable from those of $M$. lepraemurium. Moreover, the same normal and degenerate forms (Pl. 2, figs. 6-8) already described for $M$. lepraemurium were observed, but in the human material, supposedly from untreated patients, there was nearly always a much higher proportion of 
degenerate forms (mean, $55 \%$ ) than in the rat material (mean, $10 \%$ ). In one sample from a treated patient segmented forms resembling those seen in $M$. lepraemurium were observed. From the results with $\boldsymbol{M}$. lepraemurium and the comparative studies with Escherichia coli we have assumed that degenerate forms of $\boldsymbol{M}$. leprae are dead. Furthermore we found, as with $\boldsymbol{M}$. lepraemurium, that the proportion of degenerate forms of $M$. leprae seen in the electron microscope increased still further when the organisms were incubated at $37^{\circ}$ in phosphate buffer.

Unlike rat leprosy bacilli obtained from untreated animals, which nearly all stained uniformly with carbol fuchsin (Ziehl-Neelsen method), human leprosy bacilli, even from untreated patients, always showed a significant proportion of organisms which stain irregularly (generally referred to as beading). Although these beaded bacilli are well recognized it has so far been impossible to determine their biological significance because human leprosy bacilli cannot be cultured or used to infect animals. It has been suggested that they represent degenerating or dead bacilli; this is supported by the report of Davey (1959)

Table 4. Comparison of the proportion of degenerate forms of Mycobacterium leprae in the electron microscope and irregularly staining bacilli (carbol fuchsin), from untreated patients

\begin{tabular}{|c|c|c|}
\hline $\begin{array}{l}\text { Leproma } \\
\text { specimen }\end{array}$ & $\begin{array}{l}\text { Proportion degenerate } \\
\text { in electron microscope } \\
\qquad(\%)\end{array}$ & $\begin{array}{c}\text { Irregularly stained by } \\
\text { carbol fuchsin } \\
(\%)\end{array}$ \\
\hline $\mathbf{M} / \mathbf{3}$ & $50(37 / 75)$ & $54(40 / 74)$ \\
\hline $\mathrm{BC} / \mathbf{3}$ & $93(93 / 100)$ & $94(198 / 212)$ \\
\hline $\mathbf{E} / 2$ & $25(4 / 16)$ & $25(189 / 249)$ \\
\hline $\mathbf{E} / \mathbf{3}$ & $68(27 / 43)$ & $57(45 / 79)$ \\
\hline $\mathbf{M} / 4$ & $58(14 / 24)$ & $56(66 / 118)$ \\
\hline $\mathbf{M} / \mathbf{5}$ & $41(26 / 64)$ & $45(45 / 100)$ \\
\hline $\mathbf{T} / 7$ & $64(27 / 42)$ & $58(58 / 100)$ \\
\hline $\mathbf{M} / \mathbf{6}$ & $85(33 / 39)$ & $92(92 / 100)$ \\
\hline $\mathbf{T} / \mathbf{8}$ & $59(17 / 29)$ & $46(46 / 100)$ \\
\hline $\mathrm{E} / 6$ & $45(14 / 31)$ & $49(49 / 100)$ \\
\hline
\end{tabular}

who found increased proportions of beaded bacilli in patients receiving successful chemotherapy. We have therefore tried to apply electron microscopy to this problem. Comparisons could be made between the proportion of degenerate forms of bacilli seen in the electron microscope and the proportion of irregularly stained bacilli seen in the light microscope. Experience has shown that the counts of the proportion of uniformly well-stained bacilli in a film are reproducible but it is not useful to subgroup the various types of irregularly stained organisms. The results obtained with ten samples of Mycobacterium leprae are shown in Table 4. There is a sufficiently good agreement between the two proportions to suggest that human leprosy bacilli which stained irregularly with carbol fuchsin were dead. However, this correlation between the observations with the light and electron microscope did not extend to bacilli allowed to die in phosphate buffer. While the proportion of degenerate forms seen in the electron microscope increased, the proportion showing irregular staining remained unchanged. 


\section{DISCUSSION}

The normal appearance of the human- and rat-leprosy bacilli seen with the electron microscope is of organisms filled with an essentially uniform cytoplasm in which denser bodies are sometimes seen. But in addition to this form, which is relatively easy to identify, many other appearances have been described (Malfatti, 1952). It has seemed to us, however, that in all these other types the protoplasm is so degenerate that they are more likely to be non-viable forms in various stages of decay than to represent different stages in the life cycle of the bacillus, as is usually suggested. We therefore attempted the simple classification of a sample into 'normal' forms and 'degenerate' forms and tried to assess whether this gave a close enough correlation with live and dead bacilli to be of practical use in estimating viability. In view of the difficulty of making any accurate assessment of the infectivity of these organisms, the evidence necessarily had to be somewhat indirect, in particular as it applies to Mycobacterium leprae.

It was possible to classify a culture of Escherichia coli ageing at $37^{\circ}$ into normal and degenerate forms in the way proposed for the leprosy bacilli. The proportion of degenerate forms of leprosy bacilli was found to be very similar to the proportion of non-viable organisms. There was a delay of about 2 days between the decrease of viability to a certain figure and the appearance of the same proportion of degenerate forms, suggesting that this is the length of time required for a dead organism to show an obviously degenerate morphology. However, even in a completely non-viable suspension there were still about $5 \%$ of the bacilli that were not classed as degenerate, and the count may underestimate viability by about this figure. But in the case of $E$. coli the proportion of degenerate organisms did give a fair estimate of the proportion of dead organisms. The figure refers, of course, to the sample just before its fixation for observation. The conclusion, however, was shown only to be true for the type of death that occurred in an ageing culture. Killing agents such as ultraviolet radiation and dilute acid fix as well as kill the organisms and death is not then followed by morphological degeneration.

Similar considerations apply, we believe, to observations of leprosy bacilli and the degenerate count gives a useful lower estimate of viability here too; a completely non-infectious sample showed about $95 \%$ degenerate forms. At first sight there is rather a large difference between the figure of $5 \%$ degenerate organisms in a fresh sample and the finding of only about 1 in 30 infectious organisms in an animal titration of the sample. There are, however, many possible reasons why a viable organism might fail to produce infection and the degenerate count may underestimate the non-viable count by far less than these figures suggest. Since all the degenerate forms seem to be dead, there is no value in a further subdivision according to their very varied appearances.

Although this study was not primarily concerned with the detailed morphology of the leprosy bacillus as shown by the electron microscope, it has involved an examination of some tens of thousands of the organisms and some comments on a few features discussed by other workers may be of interest. Our 
observations confirm the statement (Malfatti, 1952) that there is no marked feature that distinguishes Mycobacterium leprae from $\boldsymbol{M}$. lepraemurium (nor indeed in general, in our experience, between the leprosy bacilli and the other mycobacteria).

The question of the existence of a capsule surrounding the leprosy bacillus has been raised (Chapman et al. 1959) and we can confirm that our observations of bacilli in partly purified suspensions also give no support to this idea. No sign of any structure outside the cell wall was detected. It is true that the organisms were sometimes seen surrounded by a 'halo' (e.g. see Malfatti, 1952). It was not seen in very clean preparations and on close examination it was found to consist of small particles of debris separated from the bacillus by a clear zone. The most likely explanation of the origin of the halo is that as the specimen dried the hydrophobic surface of the bacillus threw off the thin covering layer of water. The suspended debris then dried as a ring around each bacillus and on complete desiccation the organism shrank slightly away from it. A suspension that does not show this halo can be made to do so by adding a sufficient amount of soluble protein.

The 'segmented' forms we have described are very similar to the even more striking unidentified objects beautifully shown by Kölbel (1958) with Mycobacterium tuberculosis. Apparently similar objects have also been seen with the electron microscope in thin sections of $M$. tuberculosis and identified as spores (Brieger \& Glauert, 1956b). The possibility of spore formation is clearly of great importance. Spore forms have never been demonstrated in any other of the mycobacteria but, as Brieger \& Glauert pointed out, these organisms are closely related to the spore-forming Nocardia spp., a point further confirmed by a study of the chemistry of their respective cell walls (Cummins \& Harris, 1958). But the 'segmented' forms of the leprosy bacilli, despite a similar superficial resemblance to spore forms, were found to be non-viable and after a further short period of ageing frequently changed to a completely degenerate appearance. It seems unhelpful and in this case almost certainly quite inaccurate to use the word 'spore' to describe a morphological feature which has not been shown to be viable.

It is of interest that $c .55 \%$ of Mycobacterium leprae organisms examined in the electron microscope appeared dead even when isolated from apparently untreated patients, as compared with only $10 \%$ of dead bacilli from untreated animals with rat leprosy. This difference might simply reflect an infection of longer standing in man than in animals, for undoubtedly the majority of human patients from whom our samples were obtained have had the disease for several years whereas in rat leprosy the disease would be less than a year old. In the more prolonged infection more bacilli might die and accumulate in the lesions, particularly since no direct shedding of bacilli can occur through the skin, and leprosy bacilli, like mycobacteria in general, are very resistant to destruction by the host. Nevertheless, the relatively high proportion of dead bacilli found in human leprosy may indicate that man is inherently a more resistant host than other animals to leprosy infections. This idea is supported clinically by the many types of disease seen in man, which undoubtedly result 
from different degrees of resistance to leprosy. In the mouse or rat leprosy is a progressive infection and even where the disease is retarded by pre-infection vaccination with BCG the proportion of dead bacilli is not increased (R.J.W.R.; unpublished). In rat leprosy it would appear, therefore, that whether the bacilli are multiplying or resting they, by and large, remain viable. This resembles the state in which tubercle bacilli are found in lungs of mice with chronic tuberculosis; by estimating the total and viable number of bacilli present Hart \& Rees (to be published) have demonstrated a stable, but almost entirely viable, bacillary population.

The loss of viability of both Mycobacterium leprae and $M$. lepraemurium which occurs in vitro and in vivo is associated with very distinct changes in internal structure as seen with the electron microscope, changes which appear within a few days of death of the organism. Although our findings suggest that loss of viability in vivo, sooner or later, results in changes in the bacilli which can be detected by light microscopy, such changes may not be seen when death occurs in vitro. Unfortunately the practical application of the electron microscope to determine the proportion of dead organisms in studies of human leprosy is very restricted, not only because of the limited availability of the microscope, but because high concentrations of relatively pure suspensions of bacilli are required. But nevertheless electron microscopy has suggested that in any in vivo studies the light microscope may equally well be used to identify non-viable bacilli by their irregular staining with carbol fuchsin by using the ordinary Ziehl-Neelsen method. This finding supports and adds to the significance of the observation of Davey (1959) that an increased proportion of irregularly-stained leprosy bacilli is found in patients receiving successful chemotherapy. The Ziehl-Neelsen technique followed by a simple classification of the organisms as uniformly or irregularly stained may thus have a wide and useful application as a guide to the viability of leprosy bacilli obtained from man and experimental animals.

The authors particularly wish to thank Dr J. A. K. Brown (Uganda), Dr J. S. Meredith (Tanganyika), Dr E. H. Wyatt (Belgian Congo) and Dr J. A. McFadzean and Dr M. F. R. Waters (Malaya), for supplying the human leprosy tissues; and Dr A. Fuller of this Institute for the culture of Escherichia coli.

\section{REFERENCES}

Balfour-Jones, S. E. B. (1937). The experimental transmission of rat leprosy to the golden hamster (Cricetus auratus). J. Path. Bact. 45, 739.

Bishop, F. W., Suhrland, L. G. \& Carpenter, C. M. (1948). A comparative study by electron microscopy of the morphology of Mycobacterium leprae and cultivable species of Mycobacteria. Int. J. Leprosy, 16, 361.

Bradfiedd, J. R. G. (1956). Organization of bacterial cytoplasm. In Bacterial Anatomy. Symp. Soc. gen. Microbiol. 6, 296.

Brieger, E. M. \& Glauert, A. M. (1956a). Electron microscopy of the leprosy bacillus: a study of submicroscopical structure. Tubercle, Lond. 37, 195.

Brieger, E. M. \& Glauert, A. M. (1956 b). Spore-like structures in the tubercle bacillus. Nature, Lond. 178, $\mathbf{5 4 4}$. 
Brown, J. A. K. \& ReEs, R. J. W. (1959). A simple apparatus for the transport of leprosy tissue on ice. $E$. Afr. med. J. 36, 495.

Chapman, G. B., Hanks, J. H. \& Wallace, J. H. (1959). An electron microscope study of the disposition and fine structure of Mycobacterium lepraemurium in mouse spleen. J. Bact. 77, 205.

Cummins, C. S. \& Harris, H. (1958). Studies on the cell-wall composition and taxonomy of Actinomycetales and related groups. J. gen. Microbiol. 18, 173.

Davey, T. F. (1959). Diethyl dithiolisophthalate (ETIP or 'Etisul') in the treatment of leprosy: A second progress report. Leprosy Rev. 30, 141.

Garbutr, E. W., Rees, R. J. W. \& BARr, Y. M. (1958). Multiplication of rat-leprosy bacilli in cultures of rat fibroblasts. Lancet, ii, 127.

Goulding, R., Robson, J. M. \& Rees, R. J. W. (1953). Intracorneal murine leprosy and its response to isoniazid. Lancet, $i, 423$.

HaNks, J. H. (1952). The infectiousness of murine leprosy bacilli after exposure to different conditions in vitro. Int. J. Leprosy, 20, 67.

Hanks, J. H. (1954). Relationship between the metabolic capacity and the infectiousness of $M$. lepraemurium, refrigeration studies. Int. J. Leprosy, $22,450$.

KöL.BEL, H. (1958). Untersuchungen am Mycobacterium tuberculosis. Zbl. Bakt. (1. Abt.), 171, 486.

Maxfatti, M. G. (1952). Study of the morphology of Mycobacterium leprae under the electron microscope. Int. J. Leprosy, 20, 95.

McFadzean, J. A. \& Valentine, R. C. (1958). An attempt to determine the morphology of living and dead mycobacteria by electron microscopy. Proc. VII int. Congr. Leprology, Tokyo, 1958, p. 89.

McFadzean, J. A. \& Valentine, R. C. (1959). The value of acridine orange and of electron microscopy in determining the viability of $M$. lepraemurium. Trans. $R$. Soc. trop. Med. Hyg. 53, 414.

Meynell, G. G. (1958). The effect of sudden chilling on Escherichia coli. J. gen. Microbiol. 19, 380.

Morgan, J. F., Morton, H. J. \& Parker, R. C. (1950). Nutrition of animal cells in tissue culture. 1. Initial studies on a synthetic medium. Proc. Soc. exp. Biol., N.Y. 73, 1.

Mudd, S., Takeya, K. \& Henderson, H. J. (1956). Electron-scattering granules and reducing sites in Mycobacteria. J. Bact. 72, 767.

REes, R. J. W. (1957a). The chemotherapeutic activity of 'Triton WR 1339 and macrocyclon in murine leprosy. Amer. Rev. Tuberc. 76, 915.

Rees, R. J. W. (1957b). Some experimental approaches to leprosy. E. Afr. med.J. 34, 361.

Rees, R. J. W., Valentine, R. C. \& Wong, P. C. (1958). The biological significance of different appearances of rat and human leprosy bacilli as shown by electron microscopy. Proc. VII int. Congr. Leprology, Tokyo, 1958.

Rees, R. J. W. \& Wong, P. C. (1958). Limited multiplication of M. lepraemurium in tissue culture. Nature, Lond. $181,359$.

Wong, P. C. (1957). Study of the behaviour of Mycobacterium lepraemurium in the infected animal and in tissue culture. Ph.D. Thesis; University of London.

\section{EXPLANATION OF PLATES}

\section{Plate 1}

Fig. 1. Mycobacterium lepraemurium. 'Normal' form, $\times 25,000$.

Fig. 2. M. lepraemurium. 'Degenerate' form, $\times 25,000$.

Fig. 3. Escherichia coli. 'Normal' form, $\times 25,000$.

Fig. 4. $E$. coli. 'Degenerate' form, $\times 25,000$.

Fig. 5. M. lepraemurium. 'Segmented' form, $\times 50,000$. 
Journal of General Microbiology. I'ol. 22. No. 2

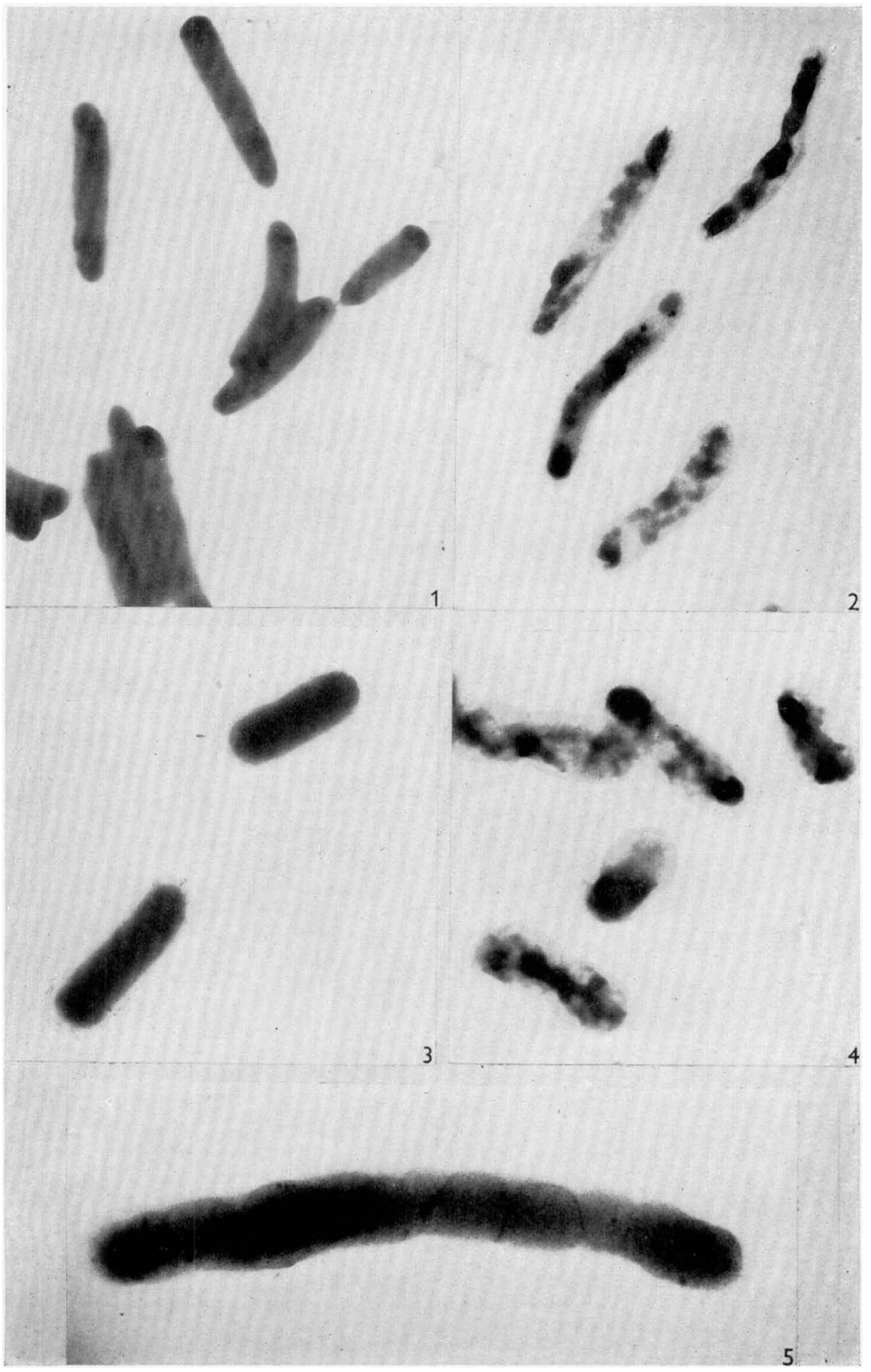

R. J. W. ReEs, R. ( LEPROSY BaCILLI. PLATE 1 
Journal of General Microbiology, Vol. 22, No. 2

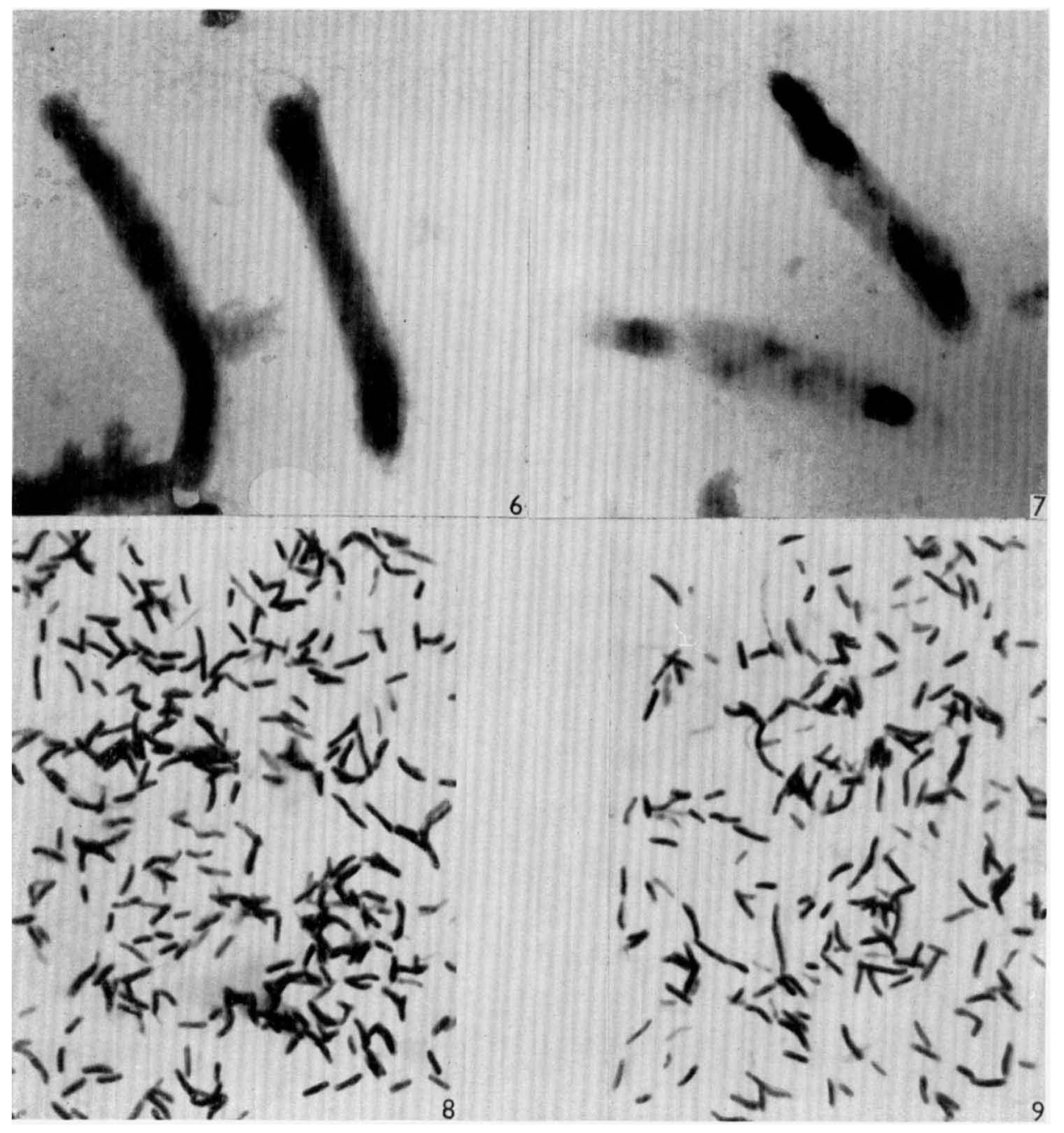

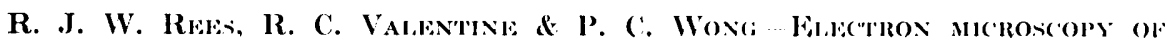
I.EPROSY BACILLI. P'IATL:? 
Prate 2

Fig. 6. Mycobacterium leprae. 'Normal' form, $\times 30,000$.

Fig. 7. M. leprae. 'Degenerate' form, $\times 30,000$.

Fig. 8. M. lepraemurium. Light microscope picture of organisms from untreated animals stained by Ziehl-Neelsen method. (The electron microscope showed mostly 'normal' forms.) $\times 3400$.

Fig. 9. M. lepraemurium. Light microscope picture of organisms from isoniazid-treated animals stained by Ziehl-Neelsen method. (The electron microscope showed mostly 'degenerate' forms.) $\times \mathbf{3 4 0 0}$.

(Received 10 September 1959) 